Article

\title{
Structural Study of Silica Coating Thin Layers Prepared from Perhydropolysilazane: Substrate Dependence and Water Penetration Structure
}

\author{
Tomotake Niizeki ${ }^{1}$, Sachiko Nagayama ${ }^{1}$, Yoshio Hasegawa ${ }^{1}$, Noboru Miyata ${ }^{2}$, Masae Sahara ${ }^{2}$ \\ and Kazuhiro Akutsu 2,* \\ 1 ART KAGAKU Co., Ltd., 3135-20 Muramatsu, Tokai, Ibaraki 319-1112, Japan; niizeki@artkagaku.co.jp (T.N.); \\ nagayama@artkagaku.co.jp (S.N.); hasegawa@artkagaku.co.jp (Y.H.) \\ 2 Comprehensive Research Organization for Science and Society (CROSS), 162-1 Shirakata, \\ Tokai, Ibaraki 319-1106, Japan; n_miyata@cross.or.jp (N.M.); m_sahara@cross.or.jp (M.S.) \\ * Correspondence: k_akutsu@cross.or.jp; Tel.: +81-29-270-5501, +81-29-219-5300 \\ Academic Editor: Massimo Innocenti \\ Received: 18 September 2016; Accepted: 16 November 2016; Published: 19 November 2016
}

\begin{abstract}
The structure of perhydropolysilazane (PHPS)-derived silica (PDS) waterproof thin layers synthesized by curing at $60{ }^{\circ} \mathrm{C}$ for $1 \mathrm{~h}$ and allowed to stand for $48 \mathrm{~h}$ at $20^{\circ} \mathrm{C}$ on various kinds of substrates was studied. Neutron reflectivity (NR) analysis suggested that uniform PDS thin layers were synthesized on the substrates, and the density of the layers varied depending on the type of substrate. Additionally, since the change in PDS density is correlated with the $\mathrm{p} K_{\mathrm{a}}$ value of the $\mathrm{OH}$ group on the substrate, it can be suggested that the acidity of the substrate would be one of the main factors determining the density of the coated PDS thin layers. For the water penetration structure study, NR analysis revealed that the depth of water penetration into the PDS layers was below $500 \AA$, and the hydration number of the $\mathrm{SiO}_{2}$ molecule was estimated to be 8.0-9.0. From these results, we concluded that water penetration occurred by the formation of water-pool structures in the PDS layers, and the randomly formed nano-air holes lead to a reduction in the probability of water penetration into the deep regions of the PDS layers.
\end{abstract}

Keywords: perhydropolysilazane; neutron reflectivity; water penetration

\section{Introduction}

Silicon-based protective coatings have been widely accepted and employed in many applications such as semiconductor devices, tablewares, and metallic substrates. Inorganic precursors, sush as perhydropolysilazane (PHPS, Figure 1), are one of the more promising materials for protection of these materials because inorganic precursors can be easily used to synthesize high-quality thin $\mathrm{SiO}_{2}$ layers by hydrolysis or oxidation [1,2]. In fact, PHPS was applied in transparent gas barrier materials [3], thin-film light addressable potentiometric sensors [4], and waterproofing layer of metal magnetic material [5]. The major concern with using silicon-based materials is that the formation behavior of $\mathrm{SiO}_{2}$ layers may change depending on the nature of the surface or condition of the PHPS-protected material. Therefore, many studies have focused on silicon-based materials and studied their $\mathrm{SiO}_{2}$ network formation mechanisms [6-9].

Bauer et al. [10] studied the influence of temperature, relative humidity, and relative humidity of an ammonia-containing atmosphere on the curing time of PHPS. Their studies revealed that the curing reaction relies mainly on the activation of $\mathrm{Si}-\mathrm{H}$ and $\mathrm{Si}-\mathrm{N}$ bonds by $\mathrm{OH}$ group containing substances such as water, which promotes subsequent cross-linking of intermediate silanols via condensation reactions. Akutsu et al. [5] studied the effect of synthesized $\mathrm{SiO}_{2}$ layer thickness on the density of $\mathrm{SiO}_{2}$ layers, and their studies showed that the density of $\mathrm{SiO}_{2}$ layers depends on the efficiency 
of cross-linking reaction between silazane oligomers in coated PHPS layers. Nevertheless, further research on the nano-structure and detailed synthesis mechanisms for the preparation of $\mathrm{SiO}_{2}$ layers is important for the development of silicon-based coating materials.

a)

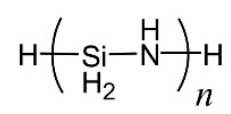

b)

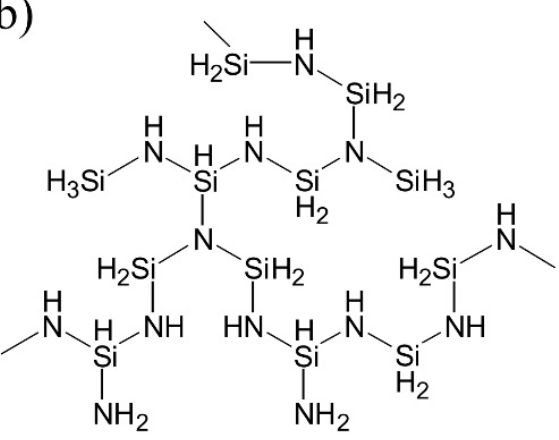

Figure 1. Composition formula (a) and structural formula (b) of perhydropolysilazane (PHPS).

A variety of techniques, such as Fourier-transform infrared spectroscopy (FT-IR) [8,11], X-ray photoelectron spectroscopy (XPS) [8,11], and neutron reflectivity (NR) [5], have been used to study the structure of PHPS-derived silica (PDS) thin layers. Since the thickness, density, and roughness of the thin layer samples can be determined by NR techniques [12,13], here we use NR techniques to elucidate the nano-structure of PDS thin layers. In this study, we prepared the PDS thin layer samples on different kinds of substrate ( $\mathrm{Si}^{-}, \mathrm{Al}_{2} \mathrm{O}_{3^{-}}, \mathrm{MgO}-$, and polyvinyl alcohol (PVA)-substrate, which are target materials for PHPS-based protective coatings), and the influence of substrate type on PDS nano-structure was investigated. Additionally, since neutron scattering is especially sensitive to water (hydrogen atom), the water penetration into the PDS thin layers was also analyzed by the NR technique. From the analyses, we elucidated the waterproof mechanism of PDS thin layers in terms of the nano-scale structure.

\section{Materials and Methods}

\subsection{Materials}

Silicon (diameter $=5.08 \mathrm{~cm}$, thickness $=0.3 \mathrm{~mm}$ ), sapphire $\left(\mathrm{Al}_{2} \mathrm{O}_{3}\right.$, diameter $=5.08 \mathrm{~cm}$, thickness $=0.43 \mathrm{~mm})$, and magnesium oxide $(10 \mathrm{~mm} \times 10 \mathrm{~mm}$, thickness $=0.5 \mathrm{~mm})$ wafers were supplied by SEMITEC Co. Ltd. (Tokyo, Japan), MKT Co. Ltd. (Kanagawa, Japan), and Crystal Base Co. Ltd. (Osaka, Japan), respectively. PHPS polymer (AQUAMICA, Product Code: NP110-10, amine catalyst type), PVA, and xylene were supplied by AZ Electronic Materials Co. Ltd. (Tokyo, Japan), Wako Pure Chemical Industries Ltd. (Tokyo, Japan), Kanto Chemical Co. Inc. (Tokyo, Japan), respectively. These compounds were used without further purification.

\subsection{Sample Preparation}

Before synthesis of thin PDS layer samples, the PVA substrate was prepared. Using a spin-coater (MS-A150, Mikasa Co. Ltd., Tokyo, Japan), the thin PVA layer was coated on the silicon wafer by spin coating $2 \%$ of PVA/water solution at a speed of $4000 \mathrm{rpm}$, and then, the sample was heated at $60{ }^{\circ} \mathrm{C}$ for $1 \mathrm{~h}$. The resulting PVA/Si substrate was used as the PVA substrate in this study.

The thin PDS layers were prepared on the silicon, sapphire, and PVA substrates by spin coating $5 \%$ of PHPS/xylene solution at a speed of $6000 \mathrm{rpm}$. In the case of the magnesium oxide substrate, the PDS layer was prepared by hand-painting of $5 \%$ of PHPS/xylene solution because the PHPS solution was repelled by the surface of the magnesium oxide substrate so no PHPS solution remained on it. Subsequently, the samples were cured at $60{ }^{\circ} \mathrm{C}$ for $1 \mathrm{~h}$ and allowed to stand for $48 \mathrm{~h}$ at 
$20{ }^{\circ} \mathrm{C}$. The samples were stored in a box under low-humidity and dust-free conditions for 7 days at room temperature.

For the water penetration analysis, thin and thick PDS layers were prepared on the silicon wafers following the same procedures described above, with the exception of the spin coating speeds being different (thin layer: $6000 \mathrm{rpm}$; thick layer: $3000 \mathrm{rpm}$ ). The synthesized PDS layer samples were submerged in purified water (Aqua Purificata, SEIKI Chemical Industrial Co. Ltd., Tokyo, Japan) for 7 days at room temperature. Before the NR measurements, the wet samples were taken out of the solution and air-dried at $20^{\circ} \mathrm{C}$ for $4 \mathrm{~h}$.

\subsection{FT-IR Measurements}

The samples for the FT-IR spectroscopic analysis were prepared by removing a section from each sample prepared for the NR measurements.

The FT-IR spectra were measured with an FT/IR-4100ST (Nihon Bunko Co. Ltd., Tokyo, Japan) system equipped with an attenuated total reflectance (ATR) unit (PRO670H-S, Nihon Bunko Co. Ltd., Tokyo, Japan). The wavenumber range $700-4000 \mathrm{~cm}^{-1}$, and the resolution was $4 \mathrm{~cm}^{-1}$. Each spectrum was determined from an average of 64 scans, and all the measurements were performed at room temperature. It must be noted that, because the refractive index of substrates $\left(\mathrm{Si}, \mathrm{Al}_{2} \mathrm{O}_{3}\right.$, and $\left.\mathrm{MgO}\right)$ are high towards ZnSe ATR prism, the total reflection phenomena cannot be observed and ART correction (program) cannot work exactly in the samples. Therefore, transmittance in the lower wavenumber region was not obtained correctly due to the above reason.

\subsection{Neutron Reflectivity Measurements and Data Analysis}

The NR measurements were performed on a BL17 SHARAKU reflectometer installed at the Materials and Life Science Experimental Facility (MLF) in J-PARC [14,15]. The incident beam power of the proton accelerator was $200 \mathrm{~kW}$ for all the measurements. Pulsed neutron beams were generated using a mercury target at $25 \mathrm{~Hz}$, and the NR data were measured using the time-of-flight (TOF) technique. The neutron-source to sample distance was $15.5 \mathrm{~m}$, and the sample to ${ }^{3} \mathrm{He}$ gas point detector distance was $2.5 \mathrm{~m}$. The wavelength $(\lambda)$ range of the incident neutron beam was tuned to be approximately $\lambda=2.2-8.8 \AA$ using disk choppers. The covered $Q_{z}$ range was $Q_{z}=0.008-0.09 \AA^{-1}$, where $Q_{\mathrm{z}}=(4 \pi / \lambda) \sin \theta$ (here, $\theta$ represents the incident angle). The incident angle for PDS $/ \mathrm{Si}, \mathrm{PDS} / \mathrm{Al}_{2} \mathrm{O}_{3}$, $\mathrm{PDS} / \mathrm{PVA} / \mathrm{Si}$, and wet-PDS/Si samples varied from $0.3^{\circ}$ to $0.9^{\circ}$, and that for the PDS/MgO sample was $0.4^{\circ}$ (because high $Q_{\mathrm{z}}$ region measurement is difficult under these sample conditions). The total exposure times for the measurements were $1 \mathrm{~h}$ for PDS $/ \mathrm{Si}, 1.5 \mathrm{~h}$ for PDS $/ \mathrm{Al}_{2} \mathrm{O}_{3}, 3.3 \mathrm{~h}$ for PDS/PVA/Si, $2 \mathrm{~h}$ for PDS/MgO, and $4 \mathrm{~h}$ for wet-PDS/Si samples, respectively. $10 \mathrm{~mm}$ (for PDS/MgO) and $25 \mathrm{~mm}$ (other samples) beam footprints were maintained on the sample surfaces by using six kinds of incident slits. The samples were placed in an aluminum sample holder on the sample stage, which was installed at the center position of the sample rotator. All the measurements were performed at room temperature.

The data reduction, normalization, and subtraction were performed using a program installed in BL17 SHARAKU that was developed for the TOF data. The Motofit program [16] was used to fit the NR profiles using the least-squares approach to minimize deviations in the fit; the thickness, scattering length density (SLD) [5], and Gaussian roughness were evaluated by the program.

\section{Results and Discussion}

\subsection{FT-IR Analysis for Thin PDS Layer Samples}

To determine the composition of the synthesized PDS layers on the different kinds of substrate, the molecular structures of the PDS layers were analyzed by FT-IR analysis. Although it seems difficult to determine the origin of the absorption peak in lower wavenumber region, here we discuss the possibility of explaining the observed absorption peaks. 
Figure 2 shows the FT-IR spectra of the PDS thin layer samples in the wavenumber range of $700-4000 \mathrm{~cm}^{-1}$. Since the FT-IR signal of PDS/MgO sample was weak compared with those of the other samples, the vertical axis scale of the PDS/MgO sample data was enlarged five times to facilitate data comparison. Absorption peaks for $\mathrm{N}-\mathrm{H}\left(3400 \mathrm{~cm}^{-1}\right)$ and Si-H $\left(2200 \mathrm{~cm}^{-1}\right)$, which are attributable to the unreacted PHPS molecule $[17,18]$, were not observed in the spectra. These results indicate that the starting PHPS material was mostly consumed during the curing reaction. However, a broad absorption peak around $880 \mathrm{~cm}^{-1}$, which would be attributable to the $\mathrm{Si}-\mathrm{N}-\mathrm{Si}$ band, was observed. Thus, it implies that the synthesized PDS layers would contain a negligible amount of Si-N-Si bonds.

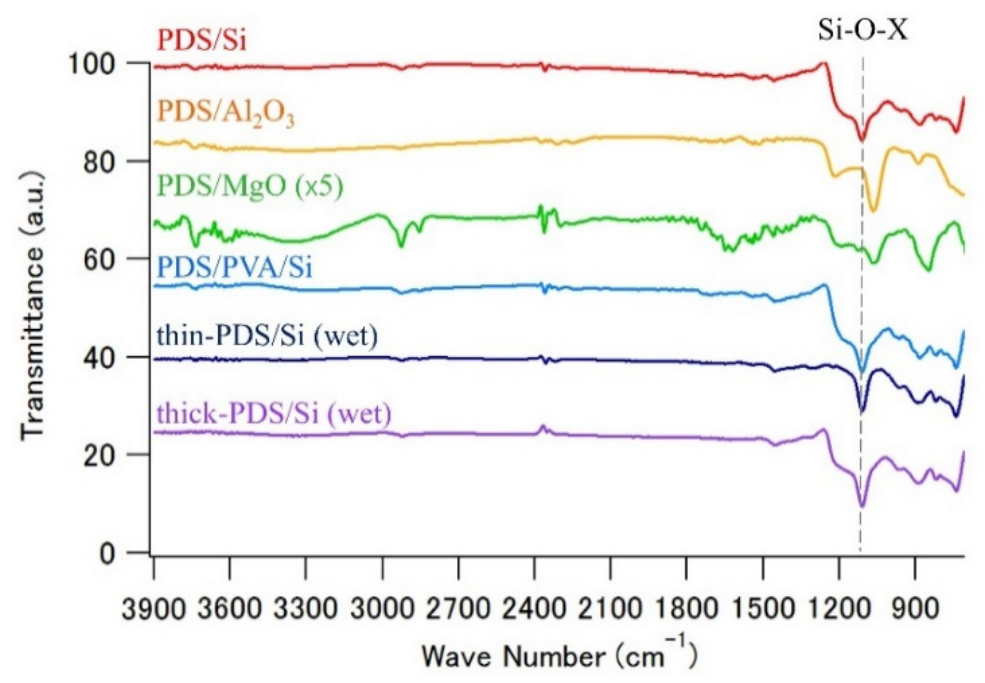

Figure 2. Fourier-transform infrared spectroscopy (FT-IR) attenuated total reflectance (ATR) spectra (mean) of the thin PHPS-derived silica (PDS) layer samples. The vertical axis scale of PDS/MgO data was enlarged to five times its original size.

In addition, the observed FT-IR spectra showed large absorption peaks in the region of $1000-1250 \mathrm{~cm}^{-1}$. These absorption peaks were mainly due to Si-O asymmetric stretching transverse optical (TO) and longitudinal optical (LO) modes [6,19]. Although the largest peak at around $1110 \mathrm{~cm}^{-1}$ can be assigned $\mathrm{Si}-\mathrm{O}(-\mathrm{Si})$ stretching $[20,21]$, the position of the largest peak was changed to a lower wavenumber for the PDS $/ \mathrm{Al}_{2} \mathrm{O}_{3}$ and PDS/MgO samples. K.M.K. Yu et al. [21] studied the FT-IR spectra of silica-alumina composite materials and reported that the presence of $\mathrm{Al}^{3+}$ as the second neighbor of the $\mathrm{Si}-\mathrm{O}$ results in the $\mathrm{Si}-\mathrm{O}$ asymmetric stretching peak being shifted towards a lower wavenumber. Similar Si-O peak shifts were investigated in silica-magnesium oxide composite materials [22]. Therefore, one explanation for the peak position changes is that the tiny amount of $\mathrm{Si}-\mathrm{O}-\mathrm{Al}$ and $\mathrm{Si}-\mathrm{O}-\mathrm{Mg}$ bonds formed in PDS/substrate interface may read the peak position change of $\mathrm{Si}-\mathrm{O}$ asymmetric stretching. Incidentally, a well-defined $\mathrm{O}-\mathrm{H}$ stretching absorption peak for water was not observed in any of the data, including the samples of the water penetration experiments. Since all the samples were stored at ambient temperature and pressure for two weeks to decrease their radioactivity, most of the water molecules vaporated during that time. In conclusion, these results suggested that the synthesized PDS thin layers primarily consisted of $\mathrm{SiO}_{2}$ and similar compounds, as determined from the FT-IR measurements.

\subsection{Neutron Reflectivity Analysis for PDS Thin Layer Samples}

The nano-structure information for the PDS thin layers on the different kinds of substrates is especially helpful in understanding the influence of the substrate on the synthesis of PDS thin layers. Thus, the nano-structure, thickness, density, and roughness of the PDS thin layers on the different substrates were examined by NR analysis. Note that since the low level background data was obtained 
in NR measurements, we believe that the PDS layer samples do not contain many hydrogen atoms because the incoherent scattering of hydrogen atom produces a high background in the NR experiment.

Figure 3 shows the NR profiles of the air-solid reflectivity data for the PDS thin layer samples. The period of the PDS/MgO thin layer data was clearly shorter those of the other data. This indicates that the thickness of the PDS/MgO thin layer is much greater than for the other samples. Because the $\mathrm{PDS} / \mathrm{MgO}$ thin layer sample was prepared by hand-painting, its thickness could not be equalized with the others. Figure 3 also shows the fitting results of these data using the Motofit reflectometry package. Because a naturally oxidized $\mathrm{SiO}_{2}$ thin layer was present on the surfaces of the $\mathrm{Si}$ substrates, a two-layer model (PDS/ $\mathrm{SiO}_{2}$ (oxidized)/Si) and a three layer model (PDS $/ \mathrm{PVA} / \mathrm{SiO}_{2}$ (oxidized) $/ \mathrm{Si}$ ) were employed to fit the obtained NR profiles. A single layer model was employed in the case of $\mathrm{PDS} / \mathrm{Al}_{2} \mathrm{O}_{3}$ and PDS/MgO thin layer samples. The symbols represent the observed NR profiles, while the solid lines represent the calculated NR profiles determined from the structural models. The theoretical reflectivity profiles reproduced the experimental NR profiles over the $Q_{z}$-range. Table 1 shows the structural parameters obtained from this analysis. The structural parameters of the PDS/Fe/Si sample, that is the results of our previous work [5], are also shown in Table 1 to highlight the influence of the substrate on PDS nano-structure. The thickness $(t)$ and scattering length density (SLD, $\rho$ ) values of the PDS thin layers were estimated to be $461 \AA$ and $2.10 \times 10^{-6} \AA^{-2}$ for $\mathrm{PDS} / \mathrm{Si}, 436 \AA$ and $1.86 \times 10^{-6} \AA^{-2}$ for PDS $/ \mathrm{Al}_{2} \mathrm{O}_{3}, 1809 \AA$ and $1.00 \times 10^{-6} \AA^{-2}$ for PDS/MgO, and $430 \AA$ and $1.99 \times 10^{-6} \AA^{-2}$ for PDS/PVA/Si samples, respectively. As mentioned above, the PDS/MgO sample was thicker than the other samples. Moreover, although the thickness of the PDS thin layers were similar except for that of the PDS/MgO sample, the SLD value for the PDS thin layer can be varied by changing the kind of substrate. Since the $\rho$ value of natural $\mathrm{SiO}_{2}$ is $3.47 \times 10^{-6} \AA^{-2}$ [23], the estimated $\rho$ values indicated that the density of the synthesized PDS thin layers was lower than either that of natural $\mathrm{SiO}_{2}$ or that of the unreacted PHPS (with a $\rho$ value of $0.40 \times 10^{-6} \AA^{-2}$ ) remaining in the PDS thin layer. It can be concluded that this change in the $\rho$ value reflected the change in the density of the PDS layer because FT-IR results indicated that no unreacted PHPS molecules remained in the PDS layers. The results also suggest that the densities of the synthesized PDS thin layers were uniform in the depth direction, and the low SLD values of the PDS layer as $\mathrm{SiO}_{2}$ may be attributed to the formation of nano-air holes inside the PDS layer.

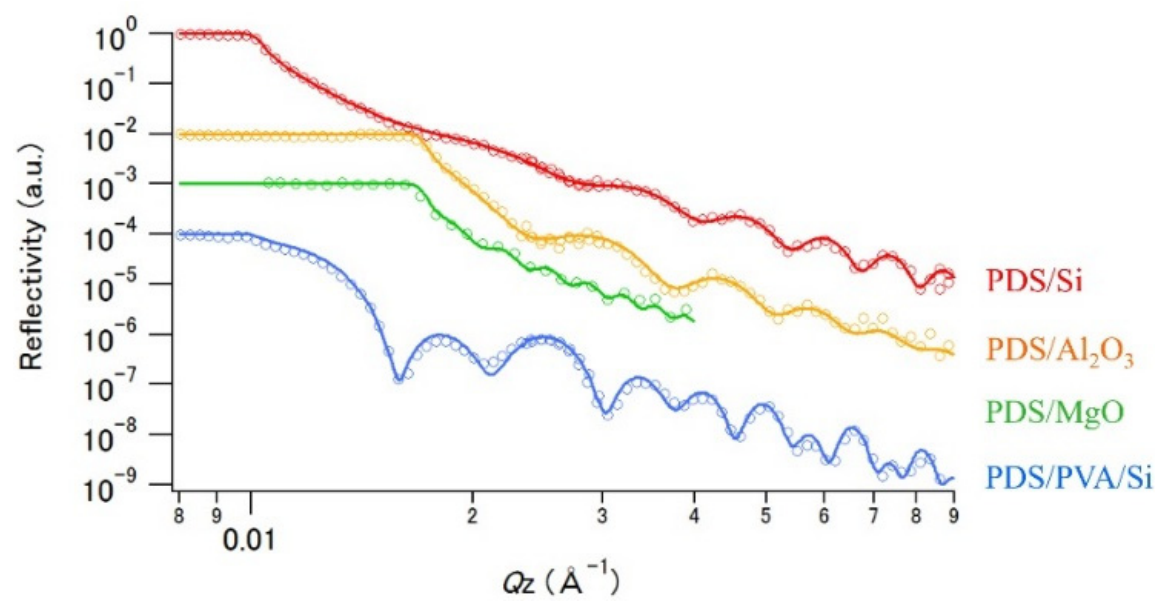

Figure 3. Neutron reflectivity profiles of the PDS thin layer samples. The circles represent the experimental data, and the solid lines represent the best-fit calculated neutron reflectivity (NR) profiles. 
Table 1. Best-fit parameters for the reflectivity model data shown in Figure 3 and reference 5.

\begin{tabular}{|c|c|c|c|c|c|}
\hline Sample & Parameter & Layer 1 & Layer 2 & Layer 3 & Layer 4 \\
\hline \multirow{4}{*}{$\mathrm{PDS} / \mathrm{Si}$} & & PDS layer & $\mathrm{SiO}_{2}$ layer & Si substrate & \\
\hline & $t(\AA)$ & 461 & 7.7 & - & \\
\hline & $\rho\left(\times 10^{-6} \AA^{-2}\right)$ & 2.10 & 3.07 & 2.07 & \\
\hline & $\sigma(\AA)$ & 3.9 & 20.7 & 4.7 & \\
\hline \multirow{4}{*}{$\mathrm{PDS} / \mathrm{Al}_{2} \mathrm{O}_{3}$} & & PDS layer & $\mathrm{Al}_{2} \mathrm{O}_{3}$ substrate & & \\
\hline & $t(\AA)$ & 436 & - & & \\
\hline & $\rho\left(\times 10^{-6} \AA^{-2}\right)$ & 1.86 & 5.74 & & \\
\hline & $\sigma(\AA)$ & 22.9 & 1.1 & & \\
\hline \multirow{4}{*}{$\mathrm{PDS} / \mathrm{MgO}$} & & PDS layer & $\mathrm{MgO}$ substrate & & \\
\hline & $t(\AA)$ & 1809 & - & & \\
\hline & $\rho\left(\times 10^{-6} \AA^{-2}\right)$ & 1.00 & 5.78 & & \\
\hline & $\sigma(\AA)$ & 2.0 & 1.6 & & \\
\hline \multirow{4}{*}{ PDS/PVA/Si } & & PDS layer & PVA layer & $\mathrm{SiO}_{2}$ layer & Si substrate \\
\hline & $t(\AA)$ & 430 & 355 & 16.9 & - \\
\hline & $\rho\left(\times 10^{-6} \AA^{-2}\right)$ & 1.99 & 0.62 & 3.34 & 2.07 \\
\hline & $\sigma(\AA)$ & 4.6 & 13.0 & 15.0 & 1.0 \\
\hline \multirow{4}{*}{$\mathrm{PDS} / \mathrm{Fe} / \mathrm{Si}[5]$} & & PDS layer & Iron oxide layer & Fe layer & $\mathrm{SiO}_{2}$ layer \\
\hline & $t(\AA)$ & 455 & 2.24 & 91.8 & 25.1 \\
\hline & $\rho\left(\times 10^{-6} \AA^{-2}\right)$ & 1.41 & 6.73 & 8.34 & 1.71 \\
\hline & $\sigma(\AA)$ & 17.5 & 1.9 & 1.9 & 2.1 \\
\hline
\end{tabular}

Thickness: $t(\AA)$, scattering length density (SLD): $\rho\left(\times 10^{-6} \AA^{-2}\right)$, surface or interface roughness: $\sigma(\AA)$.

To understand the influence of substrate on PDS nano-structure, we considered the relationship between the physical properties of the substrates and the densities of the synthesized PDS thin layers.

As shown in Table 1, the order of PDS thin layer density is PDS $/ \mathrm{Si}>\mathrm{PDS} / \mathrm{PVA} / \mathrm{Si}>\mathrm{PDS} / \mathrm{Al}_{2} \mathrm{O}_{3}>$ $\mathrm{PDS} / \mathrm{Fe} / \mathrm{Si}>\mathrm{PDS} / \mathrm{MgO}$. Since the PHPS molecule interacts with the $\mathrm{OH}$ groups of the substrates and bind the substrate surface $[5,24]$, the acid dissociation constant $\left(\mathrm{p} K_{\mathrm{a}}\right)$ was used as the physical property parameter for the substrates. According to references [25-28], the $\mathrm{p} K_{\mathrm{a}}$ values of the substrate-OH groups are in the order $\mathrm{Si}-\mathrm{OH}(7.1)<\mathrm{Al}-\mathrm{OH}(9.9)<\mathrm{PVA}-\mathrm{OH}(10.7)<\mathrm{Fe}-\mathrm{OH}(11.5)<\mathrm{Mg}-\mathrm{OH}(15.5)$ (note that the $\mathrm{p} K_{\mathrm{a}}$ value of PVA-OH is relative to the bulk state). The plot of the substrate-OH $\mathrm{p} K_{\mathrm{a}}$ values vs. the obtained SLD values of PDS thin layer is shown in Figure 4. A linear correlation between the substrate-OH $\mathrm{p} K_{\mathrm{a}}$ values and the obtained SLD values was observed. Lower $\mathrm{p} K_{\mathrm{a}}$ values indicate that the proton of the substrate-OH group is more dissociable. Accordingly, it can be assumed that substrates having lower $\mathrm{p} K_{\mathrm{a}}$ values can interact more easily with PHPS molecules (or exchange between PHPS molecules and OH protons) on the substrate-PHPS interface. That is, the MgO substrate, which has slightly dissociable substrate-OH groups, formed low-density PHPS-O-Mg structures on the surface. As a result, the density of the PDS thin layer would be lower compared with the other samples. However, because the abundance of substrate-OH groups on the substrate surface would also correlate with the resulting density of the synthesized PDS thin layer, it is difficult to conclude that the $\mathrm{p} K_{\mathrm{a}}$ value of the substrate-OH group is the fundamental reason for the changes in the density of the synthesized PDS thin layer. At least, it is clear that the $\mathrm{p} K_{\mathrm{a}}$ value of the substrate-OH group is considered one of the main factors that determine the density of the resulting PDS thin layer in this PDS layer synthesis method. 
a)

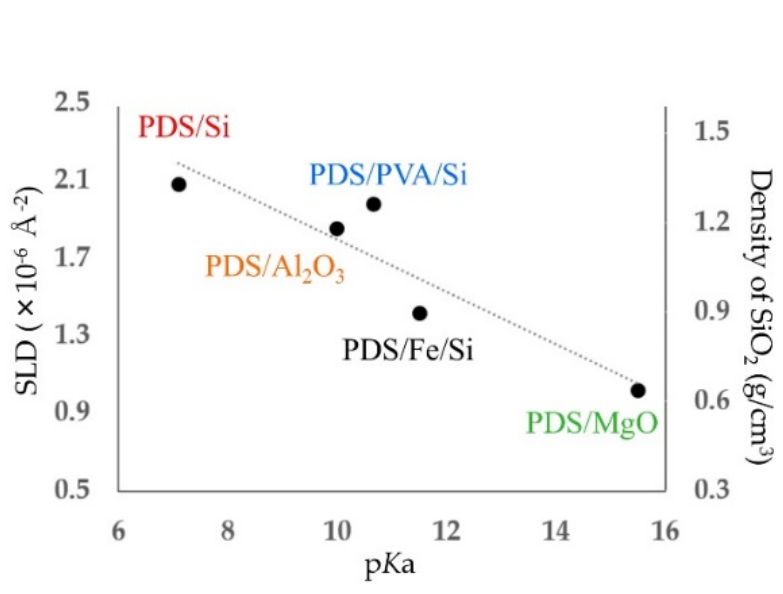

b)

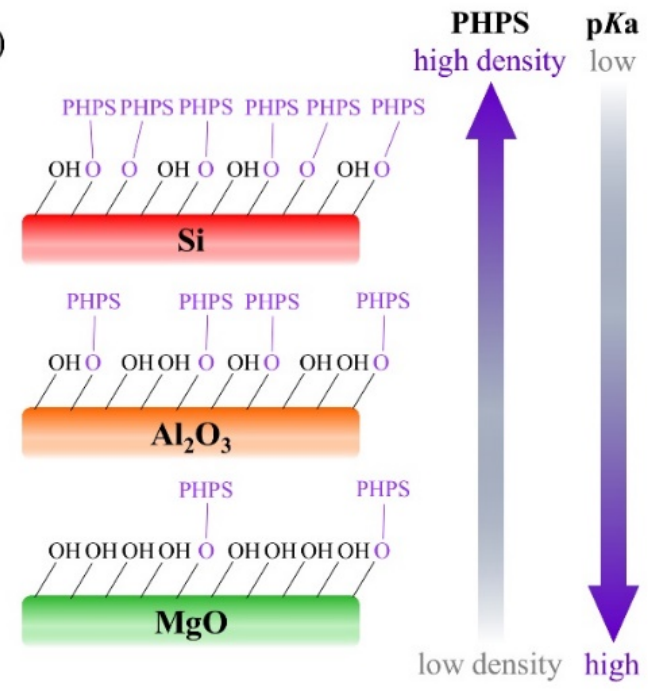

Figure 4. (a) Plot of $\mathrm{p} K_{\mathrm{a}}$ values of the substrate vs. scattering length density (SLD) values (or density of $\mathrm{SiO}_{2}$ ) of the PDS thin layer. The PDS layer density as $\mathrm{SiO}_{2}$ was calculated using the estimation method in reference 5. (b) Image of chemical bond formation between the substrate-OH group and the PHPS polymer.

\subsection{Investigation of Water Penetration Structure of PDS Thin Layer Sample}

To understand the waterproof behavior of the PDS thin layers, the depth and abundance of water penetration into the PDS thin layers were analyzed using NR analysis.

Figure 5a shows the NR profiles and fitting data for the thin and thick PDS layer samples that were submerged in deionized water for 7 days. The NR profiles of the wet samples were drastically different from those of dry ones (PDS/Si thin layer sample, Figure 3), indicating that a large amount of water penetrated into the PDS layer. Based on this fact, a four-layer model: water-rich PDS/water-poor PDS/no-water PDS/ $\mathrm{SiO}_{2}$ (oxidized)/Si, was employed to fit the obtained NR profiles. The symbols represent the observed NR profiles, while the solid lines represent the calculated NR profiles determined from the structural models. The theoretical reflectivity profiles reproduced the experimental NR profiles over the Qz-range. Table 2 shows the structural parameters obtained from this analysis. In the case of the thin PDS layer sample, the $t$ and $\rho$ values were estimated to be $73.9 \AA$ and $0.18 \times 10^{-6} \AA^{-2}$ for water-rich PDS, $261 \AA$ and $0.31 \times 10^{-6} \AA^{-2}$ for water-middle PDS, $41.5 \AA$ and $1.12 \times 10^{-6} \AA^{-2}$ for water-poor PDS, $21.9 \AA$ and $3.28 \times 10^{-6} \AA^{-2}$ for the $\mathrm{SiO}_{2}$ (oxidized) layer, respectively. On the other hand, in the case of the thick PDS layer sample, the $t$ and $\rho$ values were estimated to be $43.4 \AA$ and $0.09 \times 10^{-6} \AA^{-2}$ for water-rich PDS, $386 \AA$ and $0.34 \times 10^{-6} \AA^{-2}$ for water-middle PDS, $259 \AA$ and $2.29 \times 10^{-6} \AA^{-2}$ for water-poor PDS, $5.8 \AA$ and $3.22 \times 10^{-6} \AA^{-2}$ for the $\mathrm{SiO}_{2}$ (oxidized) layer, respectively. Since the SLD value of $\mathrm{H}_{2} \mathrm{O}$ is -0.56 [29] and lower SLD values indicate penetration of $\mathrm{H}_{2} \mathrm{O}$ molecules into the PDS layers, the obtained low SLD values, $0.09,0.18$, $0.31,0.34$, and 1.12 , clearly indicate that a large amount of water was present in the layers. Furthermore, the SLD value of the water-poor layer of the thick PDS layer sample was almost the same as that of the dry PDS layer sample [5]. It is clear that water cannot penetrate deeply into the PDS layer. Figure 5b shows the plot of the depth from the air/solid interface vs. SLD values of the wet samples (depth profile) calculated from the obtained structural parameters. The depth profiles drawn in Figure $5 \mathrm{~b}$ indicate that the extent of water penetration decreases with increasing the depth from the surface, and a large amount of water was absorbed around the surface of the PDS layers. To summarize the results, it can be concluded that the PDS thin layers having thickness over $500 \AA$ could be applied as waterproof thin layers under these experimental conditions. 
a)

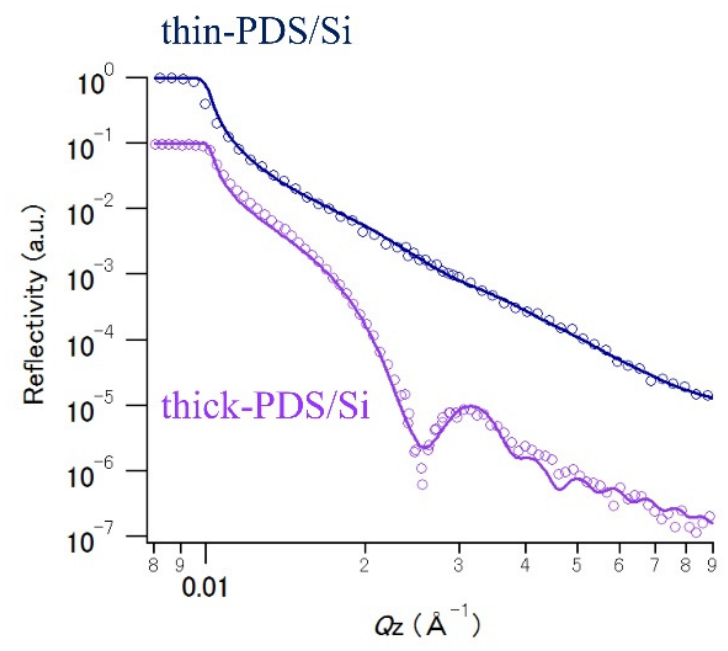

b)

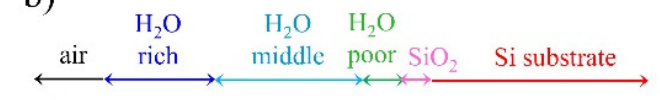
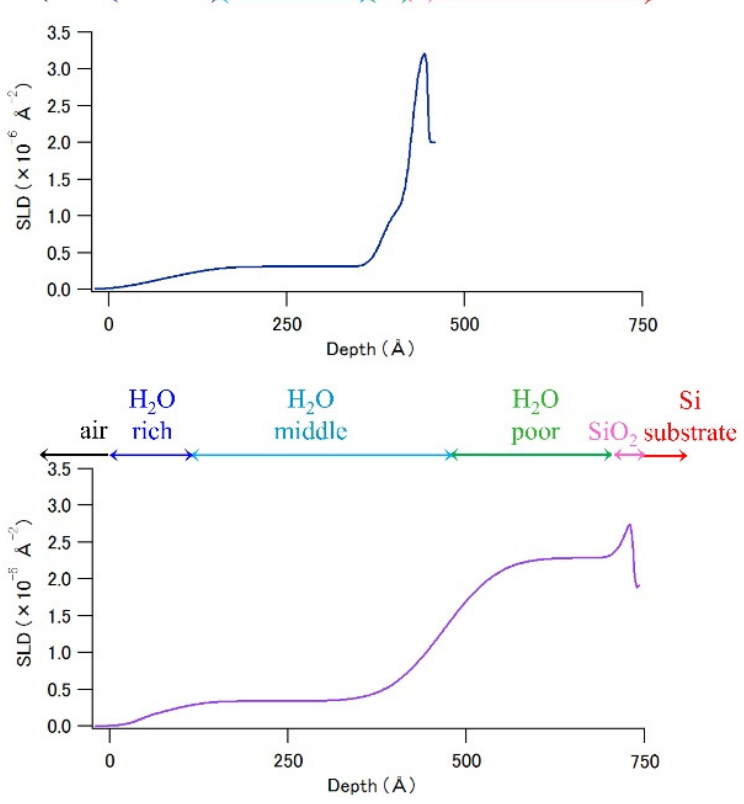

Figure 5. (a) Neutron reflectivity profiles of the thin and thick PDS layer samples in wet condition. The circles represent the experimental data, and the solid lines represent the best-fit calculated NR profiles. (b) Depth profiles of the PDS layer samples calculated by obtained structural parameters.

Table 2. Best-fit parameters for the reflectivity model data shown in Figure 5.

\begin{tabular}{ccccccc}
\hline Sample & Parameter & $\begin{array}{c}\text { Water-Rich } \\
\text { PDS }\end{array}$ & $\begin{array}{c}\text { Water-Middle } \\
\text { PDS }\end{array}$ & $\begin{array}{c}\text { Water-Poor } \\
\text { PDS }\end{array}$ & SiO $_{2}$ Layer & Si Substrate \\
\hline \multirow{4}{*}{ thin PDS/Si } & $\rho\left(\times 10^{-6} \AA^{-2}\right)$ & 73.9 & 261 & 41.5 & 21.9 & - \\
& $\sigma(\AA)$ & 0.18 & 0.31 & 1.12 & 3.28 & 2.01 \\
& & 38.1 & 37.0 & 14.3 & 9.0 & 1.7 \\
thick PDS/Si & $\rho\left(\times 10^{-6} \AA^{-2}\right)$ & 43.4 & 386 & 259 & 5.8 & - \\
& $\sigma(\AA)$ & 14.6 & 0.34 & 2.29 & 3.22 & 2.07 \\
& & 41.1 & 60.3 & 14.8 & 2.56 \\
\hline
\end{tabular}

Thickness: $t(\AA)$, scattering length density (SLD): $\rho\left(\times 10^{-6} \AA^{-2}\right)$, surface or interface roughness: $\sigma(\AA)$.

Since the SLD values of the PDS layers decrease with increasing the degree of water penetration into the layer quantitatively, we evaluated the abundance of water penetrated into the PDS layer.

The hydration number of water molecules $\left(n_{\mathrm{w}}\right)$ in the PDS layer is defined as follows [30]:

$$
\rho_{\exp }=\left(b_{\mathrm{PDS}}+n_{\mathrm{w}} b_{\mathrm{w}}\right) / V
$$

where $\rho_{\exp }, b_{\mathrm{PDS}}, b_{\mathrm{w}}$, and $V$ are the SLD values for the PDS layers obtained by NR analysis, the neutron scattering length of PDS (as $\mathrm{SiO}_{2}$ ), the neutron scattering length of $\mathrm{H}_{2} \mathrm{O}$, and the mean molecular volume of PDS, respectively. Since the values of $b_{\mathrm{PDS}}$ and $b_{\mathrm{w}}$ are constant and $\rho_{\exp }$ and $V$ can be obtained from the NR analysis data, the hydration number of water molecules can be estimated. The hydration numbers of the water-rich, water-middle, and water-poor layers in the thin PDS layer sample were estimated to be 8.6, 8.0, and 4.4, respectively. On the other hand, in the case of the thick PDS layer sample, water did not penetrate into the water-poor layer, and the hydration numbers of the water-rich and water-middle layers were estimated to be 9.0 and 8.0, respectively. Because the hydration number of 8.0-9.0 is higher for the hydrophobic $\mathrm{SiO}_{2}$ molecule, the water penetration into the PDS layers was not due to hydration for $\mathrm{SiO}_{2}$ molecules, but to the formation of water-pool 
structures in the PDS layers (this image is shown in Figure 6). In fact, the $\mathrm{SiO}_{2}$ density of the PDS layer was estimated to be $1.33 \mathrm{~g} / \mathrm{cm}^{3}$ in the PDS/Si sample, indicating that the density of the PDS layer is low compared to that of the natural $\mathrm{SiO}_{2}\left(2.2 \mathrm{~g} / \mathrm{cm}^{3}\right)$. Therefore, it is reasonable to suppose that the PDS layer has nano-air holes randomly distributed within the layer, and that the holes are transformed into water pool structures by water penetration into the PDS layer. The SEM images of the PDS layer samples [3,31] prove clearly that nano-air holes are randomly formed at the surface as well as within the PDS layers. Hence, it can be considered that the randomly formed nano-air holes lead to reduced probability of water penetration into the deep PDS layer regions.

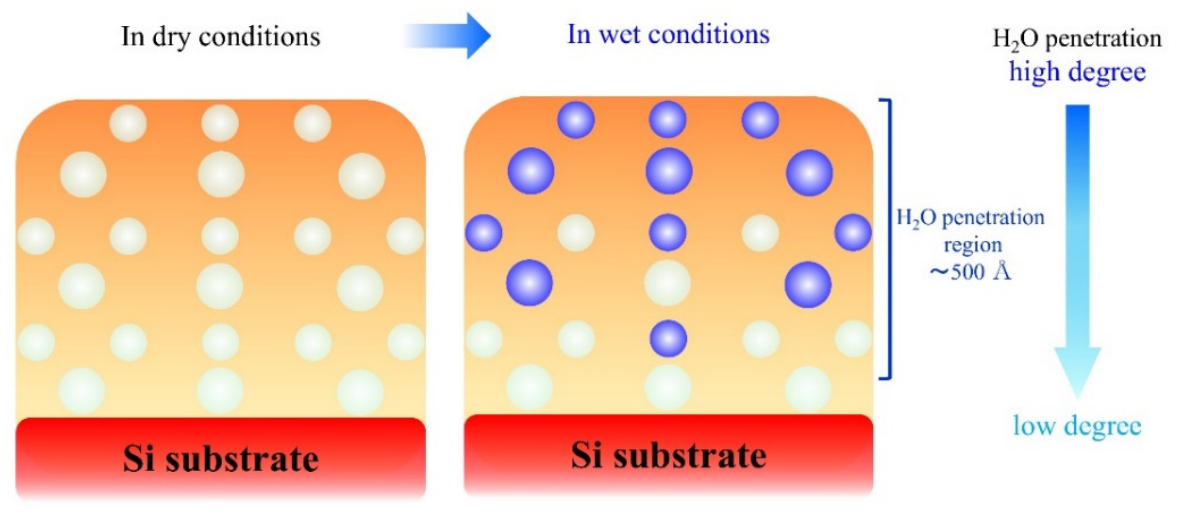

Figure 6. Illustration of the formation of water-pool structures in PDS thin layer samples in wet condition. Orange layer, white particles, and blue particles are PDS thin layer, nano-air hole, and water pool structures, respectively.

\section{Conclusions}

In this study, the structures of PHPS-derived silica (PDS) layers synthesized using perhydropolysilazane (PHPS) on various kinds of substrates were studied using Fourier transform infrared spectroscopy (FT-IR) and neutron reflectivity (NR) analysis. FT-IR data suggested that there was no starting PHPS material in the synthesized PDS layers, and the major molecular structure of the PDS layer can be represented as $\mathrm{SiO}_{2}$. The NR analysis revealed that the densities of the synthesized PDS thin layers are uniform in the depth direction, and the densities of the PDS layers are lower than natural $\mathrm{SiO}_{2}$ Therefore, it can be considered that the PDS thin layers form nano-air holes at the surface as well as within the PDS layers. In addition, the densities of PDS layers varied by changing the kind of substrate, and there was linear relationship between the density of PDS layer and the $\mathrm{p} K_{\mathrm{a}}$ value of the substrate-OH group. These results indicate that the acidity of the substrate is one of the most important factors for determination of the density of the synthesized PDS layer. The NR analysis of water penetration behavior into the PDS thin layers indicated that the hydration number of water was estimated to be 8.0-9.0, and the depth of water penetration into the PDS layers was below $500 \AA$ after 7 days of submersion in water. It can be concluded that water penetrated into the nano-air holes leading to the formation of water-pool structures in the PDS layers. Because the thickness of the actual PDS layer being applied as the waterproofing layer is about $1 \mu \mathrm{m}$, water molecules cannot penetrate into the protected material under actual use conditions.

Acknowledgments: We thank K. Soyama (JAEA, J-PARC Center) and S. Kasai (CROSS) for their support for the neutron reflectivity experiments. The neutron reflectivity experiments were conducted at the BL17 SHARAKU of the Materials and Life Science Experimental Facility (MLF) in Japan Proton Accelerator Research Complex (J-PARC), Tokai, Japan (Proposal No.2014B0055). FT-IR measurements were conducted at the User Experiment Preparation Lab III that is provided by CROSS.

Author Contributions: Tomotake Niizeki carried out the experiments and designed this study. Sachiko Nagayama carried out the experiments. Yoshio Hasegawa carried out, conceived, and designed this study. Noboru Miyata and Masae Sahawa carried out the neutron reflectivity experiments. Kazuhiro Akutsu carried out the experiments, 
analyzed the neutron reflectivity data, and wrote the original manuscript. All authors contributed to the discussion of the results and helped to revise the manuscript.

Conflicts of Interest: The authors declare no conflict of interest.

\section{References}

1. Sato, K.; Kaya, H.; Funayama, O.; Isoda, T. Evaluation of polysilazanes-perhydropolysilazane, polyborosilazane and methylhydropolysilazane-as matrix precursors of ceramic-matrix composites. J. Ceram. Soc. Jpn. 2001, 109, 440-446. [CrossRef]

2. Morlier, A.; Cros, S.; Garandet, J.P.; Alberola, N. Gas barrier properties of solution processed composite multilayer structures for organic solar cells encapsulation. Sol. Energy Mater. Sol. Cells 2013, 115, 93-99. [CrossRef]

3. Blankenburg, L.; Schrodner, M. Perhydropolysilazane derived silica for flexible transparent barrier foils using a reel-to-reel wet coating technique: Single- and multilayer structures. Surf. Coat. Technol. 2015, 275, 193-206. [CrossRef]

4. Suzurikawa, J.; Nakao, M.; Takahashi, H. Surface passivation of the thin-film LAPS with perhydropolysilazane-derived silica treated by $\mathrm{O}_{2}$ plasma. IEEJ Trans. Electr. Electron. Eng. 2011, 6, 392-393. [CrossRef]

5. Akutsu, K.; Niizeki, T.; Nagayama, S.; Miyata, N.; Sahawa, M.; Shimomura, A.; Yoshii, M.; Hasegawa, Y. Investigation of structure of a thin $\mathrm{SiO}_{2}$ layer as an antifouling and corrosion-resistant coating. J. Ceram. Soc. Jpn. 2016, 124, 172-176. [CrossRef]

6. Kozuka, H.; Nakajima, K.; Uchiyama, H. Superior properties of silica thin films prepared from perhydropolysilazane solutions at room temperature in comparison with conventional alkoxide-derived silica gel films. ACS Appl. Mater. Interfaces 2013, 5, 8329-8336. [CrossRef] [PubMed]

7. Prager, L.; Dierdorf, A.; Liebe, H.; Naumov, S.; Stojanovic, S.; Heller, R.; Wennrich, L.; Buchmeiser, M.R. Conversion of perhydropolysilazane into $\mathrm{SiO}_{\mathrm{x}}$ network triggered by vacuum ultraviolet irradiation: Access to flexible, transparent barrier coatings. Chem. Eur. J. 2007, 13, 8522-8529. [CrossRef] [PubMed]

8. Park, K.S.; Ko, P.S.; Kim, S.D. Effects of $\mathrm{N}_{2} \mathrm{O}$ plasma treatment on perhydropolysilazane spin-on-dielectrics for inter-layer-dielectric applications. Thin Solid Films 2014, 551, 57-60. [CrossRef]

9. Morlier, A.; Cros, S.; Garandet, J.P.; Alberola, N. Thin gas-barrier silica layers from perhydropolysilazane obtained through low temperature curings: A comparative study. Thin Solid Films 2012, 524, 62-66. [CrossRef]

10. Bauer, F.; Decker, U.; Dierdorf, A.; Ernst, H.; Heller, R.; Liebe, H.; Mehnert, R. Preparation of moisture curable polysilazane coatings Part I. Elucidation of low temperature curing kinetics by FT-IR spectroscopy. Prog. Org. Coat. 2005, 53, 183-190. [CrossRef]

11. Je, S.Y.; Son, B.G.; Kim, H.G.; Park, M.Y.; Do, L.M.; Choi, R.; Jeong, J.K. Solution-processable $\mathrm{LaZrO}_{\mathrm{x}} / \mathrm{SiO}_{2}$ gate sielectric at low temperature of $180{ }^{\circ} \mathrm{C}$ for high-performance metal oxide field-effect transistors. ACS Appl. Mater. Interfaces 2014, 6, 18693-18703. [CrossRef] [PubMed]

12. Yamada, N.L.; Torikai, N.; Mitamura, K.; Sagehashi, H.; Sato, S.; Seto, H.; Sugita, T.; Goko, S.; Furusaka, M.; Oda, T.; et al. Design and performance of horizontal-type neutron reflectometer SOFIA at J-PARC/ MLF. Eur. Phys. J. Plus 2011, 126, 1-13. [CrossRef]

13. Hayashida, H.; Takeda, M.; Yamazaki, D.; Maruyama, R.; Soyama, K.; Kubota, M.; Mizusawa, T.; Yoshida, N.; Sakaguchi, Y. Design and demonstration of a neutron spin flipper for a new neutron reflectometer SHARAKU at J-PARC. Phys. Proc. 2013, 42, 130-135. [CrossRef]

14. Takeda, M.; Yamazaki, D.; Soyama, K. Current status of a new polarized neutron reflectometer at the intense pulsed neutron source of the materials and life science experimental facility (MLF) of J-PARC. Chin. J. Phys. 2012, 50, 161-170.

15. Amemiya, K.; Sakamaki, M.; Mizusawa, M.; Takeda, M. Twisted magnetic structure in ferromagnetic ultrathin Ni films induced by magnetic anisotropy interaction with antiferromagnetic FeMn. Phys. Rev. B 2014, 89, 054404. [CrossRef]

16. Nelson, A.J. Co-refinement of multiple-contrast neutron/X-ray reflectivity data using MOTOFIT. J. Appl. Crystallogr. 2006, 39, 273-276. [CrossRef]

17. Launer, P.J. Infrared Analysis of Organosilicon Compounds: Spectra-Structure Correlations. Silicon Compounds Register and Review; Petrarch Systems, Inc.: Levittown, NY, USA, 1987; pp. 100-103. 
18. Mori, Y.; Saito, R. Synthesis of a poly(methyl methacrylate)/silica nano-composite by soaking of a microphase separated polymer film into a perhydropolysilazane solution. Polymer 2004, 45, 95-100. [CrossRef]

19. Yamano, A.; Kozuka, H. Preparation of silica coatings heavily doped with spiropyran using perhydropolysilazane as the silica source and their photochromic properties. J. Phys. Chem. B 2009, 113, 5769-5776. [CrossRef] [PubMed]

20. Kang, S.; Hong, S.I.; Choe, C.R.; Park, M.; Rim, S.; Kim, J. Preparation and characterization of epoxy composites ${ }^{\circledR} l$ led with functionalized nanosilica particles obtained via sol-gel process. Polymer 2001, 42, 879-887. [CrossRef]

21. Yu, K.M.K.; Thompsett, D.; Tsang, S.C. Ultra-thin porous silica coated silver-platinum alloy nano-particle as a new catalyst precursor. Chem. Commun. 2003, 13, 1522-1523. [CrossRef]

22. El-Gohary, M.I.; Tohamy, K.M.; El-Okr, M.M.; Ali, A.F.; Soliman, I.E. Influence of composition on the in vitro bioactivity of bioglass prepared by a quick alkali-mediated sol-gel method. Nat. Sci. 2013, 11, $26-33$.

23. King, S.M. Small angle neutron scattering. In Modern Techniques for Polymer Characterisation; Pethrick, R.A., Dawkins, J.V., Eds.; John Wiley \& Sons: New York, NY, USA, 1999; pp. 171-232.

24. Katagiri, K.; Takebatake, R.; Inumaru, K. Robust infrared-shielding coating films prepared using perhydropolysilazane and hydrophobized indium tin oxide nanoparticles with tuned surface plasmon resonance. ACS Appl. Mater. Interfaces 2013, 5, 10240-10245. [CrossRef] [PubMed]

25. Hair, M.L.; Hertl, W. Acidity of surface hydroxyl groups. J. Phys. Chem. 1970, 74, 91-94. [CrossRef]

26. Simmons, G.W.; Beard, B.C. Characterization of acid-base properties of the hydrated oxides on iron and titanium metal surfaces. J. Phys. Chem. 1987, 91, 1143-1148. [CrossRef]

27. Jodin, M.C.; Gaboriaud, F.; Humbert, B. Limitations of potentiometric studies to determine the surface charge of gibbsite $\gamma-\mathrm{Al}(\mathrm{OH})_{3}$ particles. J. Colloid Interface Sci. 2005, 287, 581-591. [CrossRef] [PubMed]

28. Hosny, W.M.; Khalaf-Alaa, P.A. Potentiometric study and biological activity of some metal ion complexes of polyvinyl alcohol (PVA). Int. J. Electrochem. Sci. 2013, 8, 1520-1533.

29. Yim, H.; Kent, M.S.; Tallant, D.R.; Garcia, M.J. Hygrothermal degradation of (3-Glycidoxypropyl)trimethoxysilane films studied by neutron and X-ray reflectivity and attenuated total reflection infrared spectroscopy. Langmuir 2005, 21, 4382-4392. [CrossRef] [PubMed]

30. Schalke, M.; Losche, M. Structural models of lipid surface monolayers from X-ray and neutron reflectivity measurements. Adv. Colloid Interface Sci. 2000, 88, 243-274. [CrossRef]

31. Hu, L.; Li, M.; Xu, C.; Luo, Y. Perhydropolysilazane derived silica coating protecting Kapton from atomic oxygen attack. Thin Solid Films 2011, 520, 1063-1068. [CrossRef] 